\title{
OPTIMASI RASIO Si/AI, RASIO PADATAN/CAIRAN, KONSENTRASI NaOH DAN JENIS AGREGAT DALAM SINTESA BETON GEOPOLIMER DENGAN METODE TAGUCHI
}

\author{
Ufafa Anggarini ${ }^{1, *}$, Andry Agung Pambudi ${ }^{2}$, dan Ndaru Candra Sukmana ${ }^{2}$ \\ ${ }^{1}$ Jurusan Teknik Kimia, Universitas Internasional Semen Indonesia, Jln. Veteran Kompleks PT Semen \\ Indonesia, Gresik, 61122, Indonesia
}

2Jurusan Manajemen Rekayasa, Universitas Internasional Semen Indonesia, Jln. Veteran Kompleks PT Semen Indonesia, Gresik, 61122, Indonesia

* Author Utama, email: ufafa.anggarini@uisi.ac.id

Co-author 1, email: ndaru.sukmana@uisi.ac.id

\begin{abstract}
The optimization synthezised of geopolymer based on fly ash materials have been done by using Taguchi method. The experimental design was done with 4 factors and 3 levels, that were the influence of Si/Al ratio, solid/liquid ratio, $\mathrm{NaOH}$ and the type of aggregate. Geopolymers were synthesized by sol gel method at room temperature, using fly ash as aluminasilica source and alkaline activator solutions thain consist of $\mathrm{NaOH}$ and Na2SiO3. The influence of Si/Al ratio studied at level of 4.00, 4.25, 4,50, solid/liquid ratio at level of 1.50, 2.33, 4.00. $\mathrm{NaOH}(\% w t / \% \mathrm{~V})$ of 0.24, 0.40, 0.56, and the type of aggregate of Malang sand, Bojonegoro sand and granite. Based on SNR analysis and the characterization determination of higher is better, the geopolymer optimum composition was Si/Al factor at level of 3 (4.50), solid/liquid ratio level at 2 (2.33), $\mathrm{NaOH}$ level at 1 (0.24) and type of aggregate level at 3 (granite). The calculation of compressive strength prediction was determined at $21.01 \mathrm{Mpa}$, while the optimum compressive strength of the experimental result was found at 21 Mpa.
\end{abstract}

Keywords:Geopolymer, Taguchi Method, Si/Al, Solid/Liquid, NaOH, Type of agreggate

\section{ABSTRAK}

Optimasi sintesis Geopolimer berbasis abu layang telah dilakukan dengan metode Taguchi. Desain eksperimen dilakukan dengan 4 faktor dan 3 level, yaitu pengaruh rasio Si/Al, rasio padatan/cairan, $\mathrm{NaOH}$ dan jenis agregat. Geopolimer disintesis dengan metode sol gel pada suhu kamar, menggunakan abu layang sebagai sumber aluminosilika, dan larutan alkali aktivator yang terdiri dari $\mathrm{NaOH}$ dan $\mathrm{Na2SiO3.} \mathrm{Pengaruh} \mathrm{rasio}$ Si/Al dipelajari pada level 4,00; 4,25; 4,50, rasio padatan/cairan pada level 1,50; 2,33; 4,00; $\mathrm{NaOH}$ (\%wt/\%vol) pada level 0,24; 0,4; 0,56 dan pengaruh penambahan jenis agregat pada level pasir Malang, pasir Bojonegoro dan batu granit. Berdasarkan hasil analisis SNR dan karakteristik hasil higher is better diperoleh komposisi optimum beton geopolimer pada faktor Si/Al pada level 3 (4,50), rasio padatan/cairan pada level 2 (2,33), $\mathrm{NaOH}$ pada level $1(0,24)$ dan jenis agregat pada level 3 (batu granit). Kuat tekan prediksi berdasarkan perhitungan diperoleh sebesar 21,01 MPa, sedangkan kuat tekan optimum hasil eksperimen adalah $21 \mathrm{Mpa}$.

Kata Kunci : geopolimer, metode Taguchi, Si/AI, padatan/cairan, $\mathrm{NaOH}$, jenis agregat

\section{PENDAHULUAN}

Abu layang (fly ash) digolongkan dalam limbah B3, merupakan hasil samping atau limbah proses pembakaran batu bara yang memiliki kandungan $\mathrm{SiO}_{2}$ dan $\mathrm{Al}_{2} \mathrm{O}_{3}$ yang cukup tinggi. Anggarini dkk. [1] dalam penelitiannya memanfaatkan abu layang sebagai bahan baku pembuatan beton geopolimer. Berdasarkan hasil pengujian XRF, abu layang memiliki kandungan $\mathrm{SiO}_{2}$ sebesar 46,93\% berat, dan kandungan $\mathrm{Al}_{2} \mathrm{O}_{3}$ sebesar $27,11 \%$ berat. Adanya kedua 
mineral aluminosilikat tersebut, memberikan gambaran bahwa abu layang memiliki potensi untuk dimanfaatkan sebagai bahan baku pembuatan geopolimer.

Geopolimer merupakan material dengan struktur amorf yang dapat berperan sebagai binder (pengikat) material atau material dengan kekuatan mekanikal yang tinggi [2]. Geopolimer pada umumnya disintesis dengan mencampurkan material aluminasilikat dengan larutan aktivator alkali, yang kemudian dilanjutkan dengan proses curing selama 28 hari pada suhu rendah [3]. Keberhasilan proses geopolimerisasi dalam menghasilkan material dengan kuat tekan tinggi dipengaruhi beberapa faktor. Anggarini dan Sukmana [4] menyatakan bahwa sintesis geopolimer dipengaruhi oleh rasio $\mathrm{Si} / \mathrm{Al}$, dimana semakin besar rasio Si/Al, maka kuat tekan geopolimer yang dihasilkan semakin besar. Gao dkk. [5] dalam penelitiannya menyatakan bahwa rasio padatan/cairan pada proses sintesis mempengaruhi kuat tekan geopolimer yang dihasilkan. Antonyamaladhas dkk. [6] dalam penelitiannya mempelajari pengaruh konsentrasi $\mathrm{NaOH}$ terhadap kuat tekan geopolimer hasil sintesis. Selain itu, beberapa penelitian mempelajari pengaruh penambahan jenis agregat terhadap kuat tekan geopolimer yang dihasilkan [7-8]. Berdasarkan beberapa penelitian tersebut, sintesa geopolimer dengan kuat tekan tinggi perlu mempertimbangkan faktor perancangan eksperimen berupa rasio $\mathrm{Si} / \mathrm{Al}$, rasio padatan/cairan, $\mathrm{NaOH}$ (\%berat/volume), dan penambahan jenis agregat. Optimasi pada masing-masing faktor dapat dilakukan secara simultan dengan suatu pendekatan eksperimen dengan metode Taguchi.

Metode Taguchi diperkenalkan oleh Dr. Genichi Taguchi pada tahun 1940 yang merupakan metodologi eksperimen baru yang bertujuan untuk memperbaiki kualitas produk dan proses serta dapat menekan biaya dan sumber daya seminimal mungkin [9]. Optimasi sintesis geopolimer dalam penelitian ini dilakukan dengan pendekatan metode Taguchi, dengan 4 faktor dan 3 level. Penggunaan metode ini dapat meminimalisir jumlah sampel yang seharusnya adalah 81 sampel menjadi 16 sampel dengan pendekatan matriks eksperimen seperti tercantum dalam matriks orthogonal array. Hasil analisis data yang diperoleh melalui metode Taguchi selanjutnya dapat digunakan untuk menentukan faktor eksperimen yang berpengaruh terhadap kuat tekan geopolimer dengan karakteristik higher is better. Selain itu, analisis data digunakan untuk menentukan komposisi optimum geopolimer yang menghasilkan material dengan kuat tekan tertinggi.

\section{METODE PENELITIAN}

\section{Material}

Bahan yang digunakan dalam sintesis geopolymer antara lain adalah $\mathrm{NaOH}$ pellet (teknis), $\mathrm{Na}_{2} \mathrm{SiO}_{3}$ (teknis), aquadest, abulayang (fly ash) PT Petrokimia Gresik, pasir Malang, pasirBojonegoro dan batugranit.

\section{Instrumentasi}

Peralatan yang digunakan dalam sintesis geopolymer antara lain adalah ayakan mesh No. 325, pengaduk besi, neraca 
analitik, mixer, beaker glass dan cetakan besi dimensi $5 \times 5 \times 5 \mathrm{~cm}$.

\section{Prosedur}

Sintesa geopolimer dalam penelitian ini dilakukan dengan variasi rasio $\mathrm{Si} / \mathrm{Al}$, rasio padatan/cairan, konsentrasi $\mathrm{NaOH}$ dan jenis agregat dengan faktor dan level seperti tertera pada Tabel 1.

Geopolimer dalam penelitian ini disintesis menggunakan abu layang (sumber silika alumina) yang merupakan hasil samping pembakaran batu bara PT Petrokimia Gresik.

Tabel 1. Faktor dan Level Geopolimer

\begin{tabular}{|c|c|c|c|c|}
\hline \multirow{2}{*}{$\underset{\mathbb{\Phi}}{\stackrel{\mathbb{\Phi}}{\Phi}}$} & \multicolumn{4}{|c|}{ Faktor } \\
\hline & $\begin{array}{l}\mathrm{Si} / \\
\mathrm{Al}\end{array}$ & $\begin{array}{c}\text { Padat/ } \\
\text { Cair }\end{array}$ & $\underset{(\% \mathrm{wt} / \mathrm{v})}{\mathrm{NaOH}}$ & Agregat \\
\hline-1 & 4 & 1,50 & 0,24 & PasirBojonegoro \\
\hline 0 & 4,25 & 2,30 & 0,40 & PasirMalang \\
\hline+1 & 4,50 & 4 & 0,56 & Batugranit \\
\hline
\end{tabular}

Larutan alkali activator dipersiapkan dengan mencampurkan larutan $\mathrm{NaOH}$ dan larutan $\mathrm{Na}_{2} \mathrm{SiO}_{3}$. Larutan $\mathrm{NaOH}$ dibuat dengan cara melarutkan padatan $\mathrm{NaOH}$ pada aquades. Larutan $\mathrm{NaOH}$ selanjutnya didiamkan selama 24 jam. Abu layang yang telah ditimbang selanjutnya dicampurkan dengan larutan $\mathrm{NaOH}$ dan larutan Natrium silikat dengan perbandingan komposisi seperti tertera pada Tabel2. Campuran selanjutnya diaduk hingga homogen membentuk pasta geopolimer, dan dicetak dengan cetakan kubus berdimensi $5 \times 5 \times 5 \mathrm{~cm}$. Beton geopolymer selanjutnya diuji kuat tekan pada umur 7, 14 dan 28 hari.

Eksperimen dilakukan sesuai dengan data pada matriks Orthogonal Array (OA) yang menyajikan rancangan eksperimen yang harus dilakukan.
Tabel 2.Orthogonal Array

\begin{tabular}{|c|c|c|c|c|}
\hline $\begin{array}{l}R \\
u \\
n\end{array}$ & $\begin{array}{l}\mathrm{Si} / \\
\mathrm{Al}\end{array}$ & $\begin{array}{l}\text { Padat/ } \\
\text { cair }\end{array}$ & $\begin{array}{c}\mathrm{NaOH} \\
(\% w t / v)\end{array}$ & $\begin{array}{c}\text { Jenis } \\
\text { Agregat }\end{array}$ \\
\hline 1 & 4,00 & 1,50 & 0,24 & PasirMalang \\
\hline 2 & 4,00 & 2,30 & 0,40 & PasirBojonegoro \\
\hline 3 & 4,00 & 4,00 & 0,56 & Batugranit \\
\hline 4 & 4,25 & 1,50 & 0,40 & Batugranit \\
\hline 5 & 4,25 & 2,30 & 0,56 & PasirMalang \\
\hline 6 & 4,25 & 4,00 & 0,24 & PasirBojonegoro \\
\hline 7 & 4,50 & 1,50 & 0,56 & PasirBojonegoro \\
\hline 8 & 4,50 & 2,30 & 0,24 & Batugranit \\
\hline 9 & 4,50 & 4,00 & 0,40 & PasirMalang \\
\hline
\end{tabular}

Sintesa beton geopolymer dilakukan dengan pendekatan metode optimasi Taguchi untuk meminimalisir jumlah sampel sekaligus mendapatkan kuat tekan beton optimal dengan karakteristik penelitian higher is better. Data kuat tekan sampel geopolimer pada hari ke-28 (4 replikasi) diuji normalitas untuk mengetahui bahwa data yang diperoleh adalah normal dan berdistribusi merata. Selanjutnya dilakukan uji ANOVA dengan tingkat signifikansi 5\% untuk menentukan korelasi antara factor rancangan komposisi terhadap kuat tekan geopolimer.

Faktor yang berpengaruh pada kuat tekan geopolymer selanjutnya digunakan untuk menentukan komposisi optimum. Berdasarkan rancangan komposisi optimal dari setiap factor dipilih dan dilakukan penghitungan terhadap prediksi kuat tekan optimum yang dapat dihasilkan oleh beton. Parameter higher is better dipilih karena semakin besar kuat tekan yang dihasilkan maka semakin baik kualitas beton geopolimer yang dihasilkan. Data yang didapatkan dari pengujian awal yang menghasilkan komposisi optimal dianalisis untuk membandingkan hasil kuat tekan yang didapatkan dari perhitungan dan darieksperimen. 


\section{HASIL DAN PEMBAHASAN}

\section{Analisa PengujianKuatTekanGeopolimer}

Pengujian kuat tekan geopolymer dilakukan dengan mesin uji tekan (compression test machine) pada hari ke-7, 14 dan 28, sesuai dengan SNI 03-1974-1990. Pembebanan dilakukan secara perlahan sampai beton mengalami kehancuran [10]. Hasil pengujian kuat tekan sampel geopolymer seperti tertera pada Gambar 1. Kuat tekan seluruh sampel geopolymer secara umum mengalami peningkatan mulai hari ke-7 hingga hari ke-28.

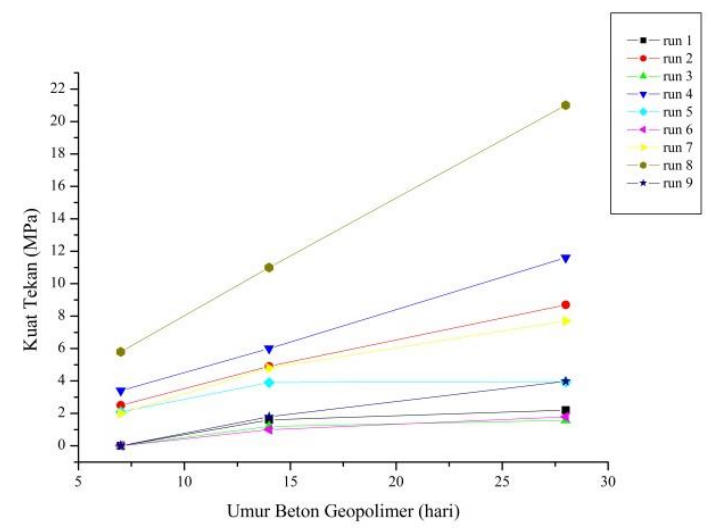

Gambar 1. Hasil uji kuat tekan sampel geopolimer hari ke 7, 14 dan 28

Kuat tekan tertinggi didapatkan pada sampel geopolimer run-8, pada hari ke-28, sebesar 21 Mpa. Kuat tekan terbesar diperoleh pada sampel geopolimer pada faktor Si/Al 4,5; rasio padatan/cairan 2,30; $\mathrm{NaOH} 0,24$ dan jenis agregat yang digunakan adalah batu granit. Sedangkan kuat tekan terendah diperoleh pada sampel geopolimer run-3, pada hari ke-28 sebesar 1,58 Mpa. Kuat tekan terbesar diperoleh pada sampel geopolimer pada faktor Si/Al 4; rasio padatan/cairan 4,00; $\mathrm{NaOH} 0,56$ dengan jenis agregat batu granit.

\section{Analisa Uji ANOVA Sampel Geopolimer}

Data kuat tekan sampel geopolimer selanjutnya dilakukan uji ANOVA (Analysis of Variance) untuk menentukan faktor eksperimen yang berpengaruh pada kuat tekan geopolimer hasil sintesis. Hasil uji ANOVA faktor yang mempengaruhi kuat tekan geopolimer hasil sintesis seperti tertera pada Tabel 3. Berdasarkan data yang diperoleh, nilai F-Hitung keempat faktor lebih besar dibandingkan F-Tabel. Hal tersebut menunjukkan bahwa dalam rasio $\mathrm{Si} / \mathrm{Al}$, rasio padatan/cairan, $\mathrm{NaOH}$ dan jenis agregat yang digunakan dalam sintesis geopolimer berpengaruh secara signifikan terhadap kuat tekan yang dihasilkan.

Tabel 3. Hasil uji ANOVA faktor rasio Si/Al, rasio

\begin{tabular}{cccccc}
\multicolumn{5}{c}{ Padatan/Cairan, NaOH dan Jenis Agregat } \\
\hline Source & $\begin{array}{c}\text { D } \\
\text { F }\end{array}$ & $\begin{array}{c}\text { Adj } \\
\text { SS }\end{array}$ & Adj MS & $\begin{array}{c}\text { F- } \\
\text { Hitung }\end{array}$ & $\begin{array}{c}\text { F- } \\
\text { Tabel }\end{array}$ \\
\hline Si/Al & 2 & 296,53 & 148,263 & 45,69 & 3,28 \\
$\begin{array}{c}\text { Padat/ } \\
\text { Cair }\end{array}$ & 2 & 462,91 & 231,457 & 71,33 & 3,28 \\
$\begin{array}{c}\text { NaOH } \\
\text { (\%wt/v) } \\
\text { Jenis }\end{array}$ & 2 & 115,85 & 57,923 & 17,85 & 3,28 \\
Agregat & 2 & 399,65 & 199,823 & 61,58 & 3,28 \\
\hline
\end{tabular}

Hal tersebut sesuai dengan penelitian Anggarini dan Sukmana [4] yang menyatakan bahwa rasio Si/Al berpengaruh pada kuat tekan geopolymer hasil sintesis. Rasio Si/Al menunjukkan jumlah kandungan silika dalam eksperimen, dimana semakin meningkatnya rasio Si/Al menunjukkan peningkatan jumlah ikatan Si-O-Si [3]. Peningkatan jumlah ikatan $\mathrm{Si}-\mathrm{O}-\mathrm{Si}$ diharapkan mampu meningkatkan kuat tekan geopolimer. Faktor rasio padatan/cairan memberikan pengaruh pada kuat tekan yang dihasilkan geopolimer. Gao dkk. [5] dalam penelitiannya menyatakan bahwa rasio padatan/cairan menunjukkan kemudahan fase padatan bahan 
aluminosilikat untuk mengalami proses disolusi dan kontak dengan larutan alkali aktivator, menghasilkan proses polikondensasi. Proses polikondensasi selanjutnya menetukan kuat tekan geopolimer yang dihasilkan.

Konsentrasi $\mathrm{NaOH}$ berpengaruh dalam proses pembentukan geopolymer dengan kuat tekan tinggi. Hamidi dkk. [11] menyatakan bahwa konsentrasi $\mathrm{NaOH}$ berperan dalam proses disosiasi spesi aktif $\mathrm{SiO}_{2}$ dan $\mathrm{Al}_{2} \mathrm{O}_{3}$ dalam abu laying untuk membentuk ikatan rantai polimer Si-O-Al. Selain itu, penambahan agregat jenis tertentu dapat meningkatkan kuat tekan geopolimer yang dihasilkan. Saker [7] dalam penelitiannya menggunakan 3 jenis agregat batugranit, pasir dan besi tulangan. Hasil penelitaiannya menunjukkan bahwa kuat tekan geopolymer dapat ditingkatkan hingga 39,5 Mpa. Berdasarkan hal tersebut, maka keempat factor penelitian berupa rasio Si/Al, rasio padatan/cairan, $\mathrm{NaOH}$ dan jenis agregat merupakan faktor yang mempengaruhi kuat tekan geopolimer.

\section{PenentuanFaktor dan Level Optimum SampelGeopolimer}

Komposisi optimum geopolymer ditentukan pada setiap faktor dan masingmasing level. Komposisi tersebut dihitung dari nilai prediksi kuat tekan yang dihasilkan geopolymer dengan karakteristik pengujian higher is better yaitu mutu yang ditentukan semakin besar maka kualitas yang dihasilkan semakin baik. Komposisi optimal selanjutnya diimplementasikan dan diuji untuk mengetahui bahwa komposisi pada faktor dan level tersebut menghasilkan geopolymer dengan kuat tekan tertinggi. Hasil uji kuat tekan sampel geopolimer yang telah mengalami proses curing 28 hari (ASTM C1074-98) dengan 4 replikasi seperti tertera pada Tabel 4.

Beberapa data menunjukkan nilai kuat tekan yang berbeda antara satu replikasi dengan lainnya. Perbedaan tersebut dikarenakan proses pencetakan yang kurang sempurna, sehingga menghasilkan material dengan retakan yang mengurangi kekuatan geopolymer ketika dilakukan uji sifat mekanik. Nilai kuat tekan sampel geopolymer selanjutnya digunakan untuk menghitung SNR pada setiap faktor dan level, sesuai Persamaan (1).

Tabel 4. Hasil Uji Kuat Tekan Geopolimer 28 Hari dan Nilai SNR Rata-rata

\begin{tabular}{|c|c|c|c|c|c|c|}
\hline \multirow{2}{*}{$\begin{array}{l}R \\
u \\
n\end{array}$} & \multicolumn{4}{|c|}{ KuatTekan(MPa) } & \multirow{2}{*}{$\begin{array}{c}\text { Kuat } \\
\text { Tekan } \\
\text { Rata- } \\
\text { rata } \\
\text { (Mpa) }\end{array}$} & \multirow{2}{*}{$\begin{array}{c}\text { SNR } \\
\text { rata- } \\
\text { rata }\end{array}$} \\
\hline & R1 & $\mathbf{R 2}$ & R3 & R4 & & \\
\hline 1 & 2,20 & 2,20 & 2,40 & 2,00 & 2,20 & 6,85 \\
\hline 2 & 11,00 & 9,00 & 5,80 & 9,00 & 8,70 & 18,79 \\
\hline 3 & 1,80 & 1,90 & 1,40 & 1,20 & 1,58 & 3,97 \\
\hline 4 & 6,60 & 14,60 & 13,60 & 11,60 & 11,60 & 21,29 \\
\hline 5 & 5,00 & 3,40 & 4,60 & 2,80 & 3,95 & 11,93 \\
\hline 6 & 2,00 & 2,00 & 1,60 & 1,50 & 1,78 & 5,01 \\
\hline 7 & 5,80 & 5,20 & 8,00 & 11,80 & 7,70 & 17,73 \\
\hline 8 & 22,00 & 21,00 & 19,20 & 21,80 & 21,00 & 26,44 \\
\hline 9 & 4,00 & 4,40 & 3,60 & 3,90 & 3,98 & 11,1 \\
\hline & & Zata-rat & $(\mathrm{Ra})$ & & 6,94 & 13,68 \\
\hline
\end{tabular}

$$
S N R=-10 \log _{10}\left[\frac{1}{n} \sum_{i=1}^{n} \frac{1}{y_{i}^{2}}\right]
$$

Nilai SNR rata-rata pada setiap faktor dan level dituliskan pada Tabel 5, dan diplotkan pada Gambar 2. Berdasarkan data pada Tabel 5 dan Gambar 2, nilai maksimum pada masing-masing faktor menunjukkan level optimum dalam sintesis geopolimer. Nilai maksimum pada faktor rasio $\mathrm{Si} / \mathrm{Al}$ diperoleh pada level 3 (4,50), faktor rasio 
padatan/cairan diperoleh pada level $2(2,30)$, faktor $\mathrm{NaOH}$ diperoleh pada level $1(0,24)$ dan faktor jenis agregat diperoleh pada level 3 (batu granit). Komposisi optimum tersebut dalam rancangan eksperimen terdapat pada run sampel ke-8. Penentuan faktor dengan level optimum selanjutnya dapat digunakan untuk menentukan kuat tekan prediksi sampel geopolimer sesuai dengan Persamaan(2).

$$
\text { KuatTekan }_{\text {prediksi }}=\overline{A 3}+\overline{B 2}+\overline{C 1}+\overline{D 3}-(3 \cdot \overline{R a})
$$

Hasil perhitungan kuat tekan prediksi dengan komposisi optimum sampel geopolymer dalam penelitian ini adalah sebesar 21,01 Mpa.

Tabel 4. Nilai SNR Rata-rata pada Setiap Faktor dan Level

\begin{tabular}{ccccc}
\hline $\begin{array}{c}\text { Lev } \\
\text { el }\end{array}$ & Si/Al & $\begin{array}{c}\text { Padatan/ } \\
\text { Cairan }\end{array}$ & $\begin{array}{c}\text { NaOH } \\
\text { (\%wt/v) }\end{array}$ & $\begin{array}{c}\text { JenisAgr } \\
\text { egat }\end{array}$ \\
\hline 1 & 4,16 & 7,17 & 8,33 & 3,38 \\
2 & 5,78 & 11,22 & 8,09 & 6,06 \\
3 & 10,89 & 2,45 & 4,41 & 11,39 \\
\hline
\end{tabular}

Nilai tersebut sama dengan nilai kuat tekan yang dihasilkan sampel geopolimer run-8 pada hari ke 28 yaitu sebesar $21 \mathrm{MPa}$. Berdasarkan analisis perhitungan, metode Taguchi dapat digunakan untuk optimasi sintesis geopolimer, dengan prinsip perbaikan mutu, meminimalisir akibat dari variasi tanpa menghilangkan penyebabnya, dan efisiensi eksperimen melalui penyusunan matriks othogonal array.

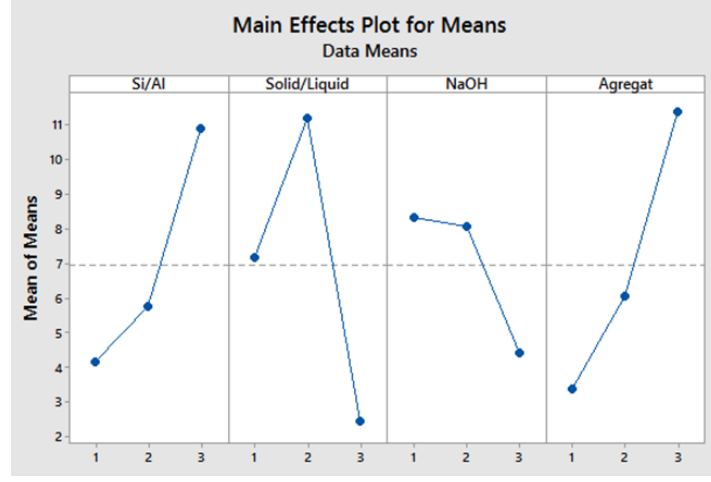

Gambar 2.Nilai SNR pada Setiap Faktor dan Level

\section{KESIMPULAN}

Sintesis geopolymer dengan kuat tekan tinggi dipengaruhi rasio Si/Al, rasio padat/cair, $\mathrm{NaOH}$ dan jenis agregat. Komposisi geopolymer dengan kuat tekan optimum dihasilkan pada rasio Si/Al 4,50; rasiopadatan/cairan 2,30; $\mathrm{NaOH} \quad 0,24$ dan jenis agregat berupa batu granit. Kuat tekan optimum sampel geopolymer hasil sintesis sesuai dengan hasil prediksi yaitu sebesar 21 Mpa.

\section{UCAPAN TERIMAKASIH}

Penulis mengucapkan terimakasih kepada LPPM UISI yang telah memberikan Hibah Riset Terapan dibawah program Hibah Riset Universitas Tahun 2017 dengan nomor kontrak 02/KP.03/11-01/05.17 tanggal 1 Maret 2017. 


\section{DAFTAR PUSTAKA}

[1] Kosada, C. and Sukmana, N.C., Penerapan Metode Taguchi pada Perancangan Eksperimen Beton Geopolimer Berbasis Abu Layang. CHEMICA: Jurnal Teknik Kimia, 4(1), pp.9-14, 2017.

[2] $\mathrm{Xu}, \mathrm{H}$. and Van Deventer, J.S.J., The geopolymerisation of alumino-silicate minerals. International journal of mineral processing, 59(3), pp.247-266, 2000

[3] Davidovits, J., Geopolymers: inorganic polymeric new materials. Journal of Thermal Analysis and calorimetry, 37(8), pp.1633-1656, 1991.

[4] Anggarini U, Sukmana NC. Synthesis and characterization of geopolymer from bottom ash and rice husk ash. InIOP Conference Series: Materials Science and Engineering 2016 (Vol. 107, No. 1, p. 012022). IOP Publishing.

[5] Gao, K., Lin, K.L., Wang, D., Hwang, C.L., Shiu, H.S., Chang, Y.M. and Cheng, T.W., 2014. Effects $\mathrm{SiO}_{2} / \mathrm{Na}_{2} \mathrm{O}$ molar ratio on mechanical properties and the microstructure of nano- $\mathrm{SiO}_{2}$ metakaolinbased geopolymers. Construction and Building Materials, 53, pp.503-510.

[6] Antonyamaladhas, M.R., Chachithanantham, S. and Ramaswamy, A., 2016. Performance and behaviour of ground granulated blast furnace slag imparted to geopolymer concrete structural elements and analyzed with ANSYS. Advances in Materials Science and Engineering, 2016.

[7] Joseph, B. and Mathew, G., Influence of aggregate content on the behavior of fly ash based geopolymer concrete. Scientia Iranica, 19(5), pp.1188-1194, 2012.

[8] Sarker, P.K., Bond strength of reinforcing steel embedded in fly ash-based geopolymer concrete. Materials and structures, 44(5), pp.1021-1030, 2011.

[9] Wahjudi, D. and Alimin, R., Rekayasa Mutu Bes Beton dengan Metode Taguchi. Jurnal Teknik Mesin, 2(2), pp.102-108, 2004.

[10] Risdiyanto, Yudi, Kajian Kuat Tekan Beton Dengan Perbandingan Volume Dan Perbandingan Berat Untuk Produksi Beton Massa Menggunakan Agregat Kasar Batu Pecah Merapi, Jurnal Tugas Akhir, Universitas Negeri Yogyakarta, Yogyakarta, Indonesia, Maret, 2013.

[11] Hamidi RM, Man Z, Azizli KA. Concentration of $\mathrm{NaOH}$ and the effect on the properties of fly ash based geopolymer. Procedia engineering. 2016 Jan 1;148:189-93. 